\title{
Importance of quantifying migraine disability in the native language of the migraineur
}

\author{
Andreas R. Gantenbein ${ }^{1,2, * \odot}$, Robin James Storer ${ }^{3 \odot}$
}

In their ranking of causes of disability, migraine is listed among the top 5 most disabling conditions by the World Health Organization [1]. Therefore, migraine is associated with a high impact on society and public health, not only through its limitation of working capacity, but also in social and leisure activities [2]. Yet migraine has " 1,000 faces," implying a broad bandwidth of clinical presentations, from patients who have the occasional headache attack to patients suffering from daily headaches. There is a correlation between the frequency of headaches and grade of disability [3], whereby meaningful disability starts at frequencies of higher than 3 days per month.

Several instruments measuring the disease-specific disability and impact on quality of life have been developed [4]. Especially with new emerging, but also more expensive treatments, there is a need to select patients suitable for these treatments [5]. One of the most frequently used scales, the Migraine Disability Assessment (MIDAS) Questionnaire, was originally developed to assess migraine-related disability in the triptan era [6]. While MIDAS is a short and relatively easy questionnaire with 7 items, it not only focuses on days with complete loss of working capacity ("absenteeism"), but also includes days with a reduced productivity ("presenteeism") over the past 90 days. Presenteeism is especially high among patients with migraine and contributes to indirect costs that are difficult to objectify [7]. Of course, scores and questionnaires will never be capable of quantifying the burden of a disease adequately. However, the availability of a questionnaire in the native language of a patient will always contribute to a better understanding of the patient's disease. Reliability and validity of the MIDAS questionnaire have been established and tested in various countries and languages. In this issue,
Asawavichienjinda et al. report testing of a Thai version of the MIDAS Questionnaire for validity, test-retest reliability, and internal consistency [8].

Author contributions. Both authors contributed to the concept of this editorial. ARG performed the literature search and RJS supervised the project. ARG wrote the original draft and RJS critically revised it. Both authors approved the final version submitted for publication and take responsibility for statements made in the published article.

Conflicts of interest statement. The authors have each completed and submitted an International Committee of Medical Journal Editors Uniform Disclosure Form for Potential Conflicts of Interest. Dr. Gantenbein reports personal fees from Grünenthal, Eli Lilly, Novartis, and TEVA, outside of the submitted work. Dr. Storer reports that he is an editor of the journal and belongs to the same institution as the author of the article whose work is the subject of this editorial.

Data sharing statement. No data sets were generated or analyzed for this work. The present editorial is based on the references cited.

\section{References}

[1] Stovner LJ, Hagen K, Jensen R, Katsarava Z, Lipton R, Scher A, et al. The global burden of headache: a documentation of headache prevalence and disability worldwide. Cephalalgia. 2007; 27:193-210.

*Correspondence to: Andreas R. Gantenbein, Department of Neurorehabilitation, RehaClinic Bad Zurzach, Quellenstrasse 34, Bad Zurzach CH-5330, Switzerland, e-mail: a.gantenbein@rehaclinic.ch

'Department of Neurorehabilitation, RehaClinic, Bad Zurzach CH-5330, Switzerland

2Department of Neurology, University Hospital Zurich, Zurich CH-8091, Switzerland

${ }^{3}$ Office of Research Affairs, Faculty of Medicine, Chulalongkorn University, Bangkok 10300, Thailand

O Open Access. $\odot 2020$ Gantenbein and Storer, published by Sciendo. (๔) BY-NC-ND This work is licensed under the Creative Commons Attribution NonCommercial-NoDerivatives 4.0 License. 


\section{Allli ASIAN BIOMEDICINE}

[2] Linde M, Gustavsson A, Stovner LJ, Steiner TJ, Barré J, Katsarava $\mathrm{Z}$, et al. The cost of headache disorders in Europe: the Eurolight project. Eur J Neurol. 2012; 19:703-11.

[3] Ford JH, Jackson J, Milligan G, Cotton S, Ahl J, Aurora SK. A real-world analysis of migraine: a cross-sectional study of disease burden and treatment patterns. Headache. 2017; 57:1532-44.

[4] Buse DC, Sollars CM, Steiner TJ, Jensen RH, Al Jumah MA, Lipton RB. Why HURT? A review of clinical instruments for headache management. Curr Pain Headache Rep. 2012; 16:237-54.

[5] Stewart WF, Lipton RB, Kolodner K. Migraine disability assessment (MIDAS) score: relation to headache frequency, pain intensity, and headache symptoms. Headache. 2003; 43:258-65.
[6] Stewart WF, Lipton RB, Dowson AJ, Sawyer J. Development and testing of the Migraine Disability Assessment (MIDAS) Questionnaire to assess headache-related disability. Neurology. 2001; 56(6 Suppl 1):S20-8.

[7] Allen D, Hines EW, Pazdernik V, Konecny LT, Breitenbach E. Four-year review of presenteeism data among employees of a large United States health care system: a retrospective prevalence study. Hum Resour Health. 2018; 16:59. doi: 10.1186/s12960-018-0321-9

[8] Asawavichienjind T, Imruetaijaroenchoke W, Phanthumchinda K. Thai-version Migraine Disability Assessment (MIDAS) Questionnaire: concurrent validity, test-retest reliability, internal consistency, and factors predictive for migraine-related disability. Asian Biomed (Res Rev News) 2020; 14(4):139-50. 